\title{
STOCK RETURNS DURING RELIGIOUS HOLIDAYS: THE ROLE OF CULTURE AND BELIEF
}

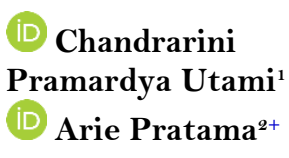

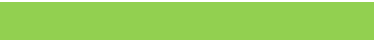

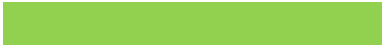

Article History

Received: 9 August 2021 Revised: 13 September 202 Accepted: 6 October 2021 Published: 29 October 2021

\section{Keywords}

Stock return

Culture

Belief

Power distance

Individualism

Uncertainty avoidance

Long-term orientation

Government regulation

Government favoritism

Social regulation.

\author{
${ }^{1,2}$ Accounting Department, Faculty of Economics and Business, Universitas \\ Padjadjaran, Indonesia. \\ 'Email: chandrarini17001@mail.unpad.ac.id \\ ${ }^{2}$ Email: arie.pratama@fe.unpad.ac.id
}

Contribution/Originality: This study contributes to the existing literature by examining the relationship between culture and belief in Asian and European countries and their effects on stock returns. This study is one of the few studies investigating international investor behavior in the stock market.

\section{INTRODUCTION}

De Anca \& Aragón (2018) state that diversity shapes identity. Identity is defined as the characteristics that distinguish one individual from another. Demographic diversity forms the identities of origin, experiential diversity forms the identities of growth, and cognitive diversity forms the identities of aspiration. The diversity of identity formation also affected the research conducted by Rossi \& Gunardi (2018) on the month's effects on the stock market in several European countries. One of the results from their study stated that Germany had a positive excess return in April, whereas Spain had a negative return in May, while Germany was only found to have a negative return in September. These differing results show that the demographic diversity that forms the identities of origin causes differences in the decisions of the individual stock market stakeholders, so differences in finding positive and negative stock returns occur. The difference in the personality and identity of each individual shows a different mindset and will result in different decisions. Research conducted by Ji, Zhang, \& Guo (2008) showed that the decisions in buying and selling shares made by Canadians based on stock price movements were different from those of the Chinese. Canadians make more linear predictions and assume that current stock price movements will 
continue, while Chinese people think stock price movements will change in the future. These results imply that more Canadians buy stocks at rising prices, while Chinese people prefer to buy stocks at declining prices.

One market anomaly can be found during holidays and is known as the holiday effects anomaly. It was found that stock returns were higher during holidays compared to other days throughout the year. Each region commemorates different holidays, including religious holidays, national holidays, and secular holidays. These facts showed that religion influences a person's actions on certain holidays. For example, Christians celebrate Christmas religiously. However, it is possible for those who are not Christians to join in celebrating Christmas. Khan, Lindridge, \& Pusaksrikit (2018) found that Muslims in United Kingdom also celebrate Christmas, one of the most significant holidays in the UK, where Christianity is the dominant religion. Muslims take part in the celebrations in their surrounding environment, not religiously but as a social gathering. It can be concluded that the larger the number of adherents of beliefs in a country, the broader and more open the scale of the commemoration of a holiday.

The market anomaly found before the commemoration of religious holidays was caused by a change in investor mood. In his research, Al-Ississ (2015) found that stock returns increased before Ramadan and decreased before Ashura. This result supports the hypothesis in this study regarding the effect of mood on the same return during religious holidays. The study shows results that support the hypothesis that stock returns will increase during Ramadan due to the mood of investors in welcoming the acceptance of blessings and forgiveness of sins, while stock returns will decrease during Ashura due to negative moods that come from anger and sadness of mourning. The results of this research on the types of contradictory moods provide a clearer picture and strengthen the statements in previous studies on the effect of mood on stock returns. Culture and belief are two things that still attract attention in research. To research these two aspects, Hofstede (1980) and Grim \& Finke (2006) generated data sets that could be used in quantitative research on culture and belief. Hofstede built six dimensions of culture that explain how people in a country think and act according to that country's culture. Each country has a value that tends toward a particular direction, so it can be seen how the characteristics of the culture of the people of a country differ. Of the six dimensions built by Hofstede, researchers found four of them related to this research, namely the Power Distance Index, Individualism versus Collectivism, the Uncertainty Avoidance Index, and Long Term Orientation. Recognizing a country's culture will help us to understand how people in that country make decisions and how people behave towards other cultures and show how each country has a different culture.

Nofsinger (2005) found that social mood influences financial decisions, where a good (high) mood triggers a psychological trap that causes abnormal stock price increases and disrupts investment decisions. Therefore, the movement of investors' moods during religious holidays that lead to abnormal returns is triggered by the religion adopted by the investor. Implementing holiday celebrations in a country also does not escape the conditions of freedom felt in that country. Grim \& Finke (2006), in their research, developed three indices that explain how a section of society responds to the religion that exists in a country, namely the Government Regulation Index (GRI), Government Favoritism Index (GFI), and Social Regulation Index (SRI). The three indices explain how religious activities in a country can be carried out.

Culture forms a person's identity that encourages a certain mindset when looking at life and making decisions, while belief can encourage someone's view to be based on a particular thing. Plopeanu, Brailean, \& Arsene (2012) state that culture and belief influence welfare in Europe, where cultural differences can stimulate economic development, and religious freedom means that economic freedom can lead to prosperity. National culture has a significant relationship with financial decisions, thus influencing trading financial instruments (Tan, Cheong, \& Zurbruegg, 2019). On the other hand, the commemoration of religious holidays builds a cheerful mood, especially for religious adherents who celebrate it (Bley \& Saad, 2010), thereby stimulating a tendency to invest (Mansour \& Jlassi, 2014). Previous studies have only focused on one aspect of culture or belief, one religion, one stock market, and not all variables related to the culture and belief were examined. For example, Lingaraja, Paul, \& Selvam (2019) focused on how stock returns were affected by the Indian culture based on the lunar phases. Wasiuzzaman \& Al- 
Musehel (2018) studied the effect of Ramadan month on stock returns. However, this study explores all the culture and belief-related variables in the 17 stock markets worldwide and can therefore potentially provide more robust and representative results about how an investor's behavior is affected by culture and belief. This study also aims to determine the extent to which culture and belief affect stock returns during religious holidays. The results of this study are expected to provide benefits for various parties both theoretically and practically. The contributions of this research include thoughts and insights about the relationship between culture and belief on stock returns in Asia and Europe during religious holidays; an overview of the condition of stock movements during religious holidays on stock markets in Asia and Europe for investors; an overview for investors regarding the potential riskreturn in investment through awareness of the emotional and psychological effects of religious holidays on stock markets in Asia and Europe; and assistance for investors' investment decisions in foreign stock markets based on the behavioral effects found in Asia and Europe. The rest of the paper is structured as follows: Section 2 discusses the literature review, Section 3 provides the research methodology, Section 4 presents the results, and Section 5 concludes the article.

\section{LITERATURE REVIEW}

This study employs the behavioral theory of finance, which states that investors' actions are not always driven by the market mechanism or rationalities (Costa, Carvalho, \& Moreira, 2019; Sharma \& Kumar, 2019). A holiday in the stock market is a moment where the investor can take action based on the psychological effect of the holiday (Robins \& Smith, 2019), for example, in a Muslim majority country, the holy month of Ramadan can increase stock returns, since investors expect to realize their returns at the end of Ramadan month (Lai \& Windawati, 2017). Holidays in a country can also be influenced by government regulation and actions (Rossi, Marcarelli, Ferraro, \& Lucadamo, 2020). Hence, this study describes the interaction between culture, belief, and the social-political context. The Power Distance Index (PDI) describes the relationship between two parties, society and government. Hofstede (2001) defines power distance as the degree to which a less powerful part of society expects and accepts that honor and power are distributed unequally. If viewed in a national context, it can be said that the more powerful part of society is the government, and the less powerful part is the people under the government's authority. People with large power distance values tend to rely on centralized authority, accept the power structure, and are reluctant to dispute directions from the authorities (Laufer, Garrett, \& Ning, 2018). In this situation, the part of society that is less powerful is passive to government regulations. If the government prefers a particular religion, it is less likely that people will have different preferences, and this preference also applies to other power levels, such as in villages, organizations, and businesses. Therefore, the celebration of a particular holiday will be more pronounced if the holiday is a commemoration within the dominant religion. In the stock market context, returns can be affected by the actions of the dominant group of investors that observe specific religious holidays (Gaganis, Hasan, Papadimitri, \& Tasiou, 2019a).

People in western regions are defined as individualistic (IDV), while people in eastern regions are collectivistic. Nguyen \& Truong (2013) mention that high levels of individualism are associated with western cultures, and high levels of collectivism are associated with eastern cultures. Individualism describes a society where the bonds between each individual are free; that is, each person is expected to take care of their own interests and close family only. In contrast, collectivism describes a society in which everyone integrates and unites into a strong group and continue to protect each other as a form of loyalty (Hofstede, 2001). Hofstede (1980) states that an individualistic person is more likely to have a high level of tolerance for uncertainty and ambiguity. Individualistic countries are considered to follow a specific cultural model (Plopeanu et al., 2012), so they are not easily influenced by the entry of foreign cultures. Therefore, the celebration of holy days continues to follow the country's culture based on the dominant religion that has shaped the country's condition from the start. Individualistic investors will make decisions independently and can therefore create an abnormal return based on his/her own decisions (Cheon \& Lee, 
2018). The Uncertainty Avoidance Index (UAI) is the degree to which a society feels comfortable with ambiguity and uncertainty (Hofstede, 2001). Nguyen \& Truong (2013) stated that people with high levels of uncertainty avoidance tend to be more conservative, and uncomfortable and reluctant in situations that change the status quo and create uncertainty. Edwards (1968) conducted psychological studies that stated that conservative individuals were slower to change their beliefs when faced with new facts (Nguyen \& Truong, 2013). This result shows that people with a high level of uncertainty avoidance view the arrival of a new culture as something that needs to be watched. Therefore, in countries with high uncertainty avoidance, it is assumed that the celebration of holidays will impact stock returns if the celebrations are part of the commemoration of the country's dominant religion (Dou, Truong, \& Veeraraghavan, 2016).

The time orientation that divides the dimensions of national culture, according to Hofstede (1980), is divided into long-term orientation (LTO) and short-term orientation (STO). The orientation of time illustrates the difference in how the people of a country view tradition and modernization. Long-term orientation is the development of virtues oriented to future rewards, namely perseverance and thrift. At the same time, short-term orientation is the development of virtues oriented to the past and present, such as respect for tradition, preservation of appearance, and fulfilling social obligations (Hofstede, 2001). People with a low long-term orientation prefer to maintain existing traditions and norms and view societal change with prejudice. With a tendency to maintain the older aspects of culture in countries with a low LTO index, it is assumed that stock returns will be affected if holiday commemorations are included in the dominant religion's activities (Flammer \& Bansal, 2017).

The Government Regulation Index (GRI) is, according to Grim \& Finke (2006), the form of regulation that received the most attention from theoretical and research perspectives. The limits set by the state can be in the form of written law or, most commonly, in the form of restrictions in the field of administration. If a country restricts the freedom of a particular religion, then the people in that country cannot easily commemorate religious holidays on a large scale and the holiday will not have a significant impact on the country's condition. On the other hand, if the state provides freedom for people to move according to their religion, then the celebration of holidays will be more readily accepted by the wider community, even by those who do not religiously commemorate the event. This freedom will also trigger the emergence of a good mood in society. In the stock market context, government regulation can help eliminate uncertainty in business and industry and induce more significant stock returns (Huang, Miao, \& Wang, 2019).

Grim \& Finke (2006) defined the Government Favoritism Index (GFI) as a subsidy, privilege, assistance, or support provided by the state for a particular religion. This attitude can take various forms, such as constitutional privileges, financial assistance for religious institutions, and even teaching religion in schools established by the state. In some countries, state leaders are also associated with religious group leaders. For example, the head of state of Great Britain is also the supreme governor of the Church of England. Through this position, the head of state of the United Kingdom indirectly promotes Christianity through their actions to affect society according to a particular religion. The head of state of the United Kingdom also gives an annual live Christmas speech. Speeches broadcast throughout the country will certainly give the public the impression of a more profound Christmas atmosphere. Khan et al. (2018) found that the Christmas atmosphere was so intense that even Muslims in the UK celebrated Christmas solely as part of a social gathering. The commemoration of religious holidays that have more support from the government has the potential to run better and on a broader scale, allowing more sections of society to celebrate and feel the impact of the celebrations. If the government provides a more favorable policy for a particular religion, then investors will use the moment to maximize their returns (Setayesh \& Daryaei, 2017).

Based on the definition put forward by Grim \& Finke (2006), the Social Regulation Index (SRI) is a limitation applied to the implementation of religious activities, religious professions, or the selection of religion by groups, associations, or other religious cultures. Religious diversity in society can trigger the emergence of social hostility, such as the threat of coercion against a particular religious norm or coercion to expand the perspective of a religion 
(Grim, 2014). The awakened mood in society affects financial decisions, such as a high (good) atmosphere causing an abnormal increase in stock prices and disrupting investment decisions (Mansour \& Jlassi, 2014; Shen, Wu, \& Chand, 2017). If there is a conflict between religions, then a good mood will be challenging to achieve. In this condition, holiday celebrations are assumed not to affect investment decisions and stock returns. Religious holidays are celebrated with primarily religious purposes. Therefore, only followers of a particular religion will religiously commemorate the holidays in that particular religion. Research by Khan et al. (2018) shows that Muslim communities in the UK celebrate Christmas only for social purposes without absorbing its essence from the religious side. Nonetheless, this particular finding does not guarantee that this happens in all countries. It is still possible that the celebration of holidays is only carried out by adherents of the religion concerned in a country. The impact of the dominant religion can also be seen from research conducted by Bley \& Saad (2010). The study found an anomaly, namely an instant price increase, before the Eid al-Fitr celebrations in most countries in the GCC (Gulf Cooperation Council) region, while the holiday effects during Christmas and New Year were not found in all of these countries.

The following hypotheses are proposed in this research:

H1: Power Distance Index (PDI) affects stock returns in Asian and European stock markets during religious holidays.

H2: Individualism Index (IDV) affects stock returns in Asian and European stock markets during religious holidays.

H3: Uncertainty Avoidance Index (UAI) affects stock returns in Asian and European stock markets during religious holidays.

H4: Long-term Orientation Index (LTO) affects stock returns in Asian and European stock markets during religious holidays.

H5: Government Regulation Index (GRI) affects stock returns in Asian and European stock markets during religious holidays.

H6: Government Favoritism Index (GFI) affects stock returns in Asian and European stock markets during religious holidays. H7: Social Regulation Index (SRI) affects stock returns in Asian and European stock markets during religious holidays.

\section{RESEARCH METHODS}

The population in this study consists of stock market indices in Asia and Europe. The sampling technique used in this research is purposive sampling. Based on the criteria set out in Table 1, from a total population of 78 stock market indices in Asia and Europe, a sample of 17 stock market indices was obtained, which was observed for the period 2016-2020. The study was conducted using stock returns one day and two days before holiday celebrations, indicated by dummy numbers on each religious classification's anniversary.

Table 1. Sampling criteria.

\begin{tabular}{l|c}
\hline Criteria & Total \\
\hline Index on stock markets operating in Asia and Europe from 2016 to 2020 & 78 \\
\hline $\begin{array}{l}\text { Stock market indices representing one particular country (not a combination of } \\
\text { countries) }\end{array}$ & 73 \\
\hline Stock market indices are listed in the top world indices on www.finance.yahoo.com & 19 \\
\hline Stock markets or countries observed commemorating religious holidays & 19 \\
\hline (Each country is only represented by one index) & $(2)$ \\
\hline Final sample & 17 \\
\hline
\end{tabular}

The 17 stock market indices included in the research sample:

1. Nikkei 225 - Japan

2. Hang Seng Index - Hong Kong

3. SSE Composite Index - China

4. STI Index - Singapore

5. S\&P BSE SENSEX - India

6. Jakarta Composite Index - Indonesia

7. FTSE Bursa Malaysia KLCI - Malaysia 
8. KOSPI Composite Index - South Korea

9. TSEC weighted index - Taiwan

10. TA-125 - Israel

11. EGX 30 Price Return Index - Egypt

12. FTSE 100 - United Kingdom

13. DAX Performance Index - Germany

14. CAC $40-$ France

15. BEL 20 - Belgium

16. MOEX Russia Index - Russia

17. BOVESPA - Brazil

The operationalization of variables in this research is shown in Table 2 below:

Table 2. Operationalization of variables.

\begin{tabular}{|c|c|}
\hline Variable & Definition \\
\hline $\mathrm{X}_{1}-\mathrm{PDI}$ & $\begin{array}{l}\text { Index }(0-100) \text { expressing the degree to which a less powerful part of society expects and } \\
\text { accepts that honor and power are distributed unequally. The closer to } 100 \text {, the higher the } \\
\text { power distance level. }\end{array}$ \\
\hline $\mathrm{X}_{2}-\mathrm{IDV}$ & $\begin{array}{l}\text { Index }(0-100) \text { expressing a society where the bonds between each individual are loose. The } \\
\text { closer to } 100 \text {, the higher the level of individualism. }\end{array}$ \\
\hline $\mathrm{X}_{3}-\mathrm{UAI}$ & $\begin{array}{l}\text { Index }(0-100) \text { expressing the degree to which a society feels comfortable with ambiguity and } \\
\text { uncertainty. The closer to } 100 \text {, the higher the level of uncertainty avoidance. }\end{array}$ \\
\hline $\mathrm{X}_{4}-\mathrm{LTO}$ & $\begin{array}{l}\text { Index }(0-100) \text { expressing the development of virtues that are oriented toward future rewards. } \\
\text { The closer to } 100 \text {, the higher the level of long-term orientation. }\end{array}$ \\
\hline$\overline{\mathrm{X}_{5}-\mathrm{GRI}}$ & $\begin{array}{l}\text { Index }(0-10) \text { stating the level of limitation on implementing religious activities, religious } \\
\text { professions, or religious elections regulated in state laws, regulations, or administrative } \\
\text { actions. The closer to } 10 \text {, the higher the level of government regulation. }\end{array}$ \\
\hline $\mathrm{X}_{6}-\mathrm{GFI}$ & $\begin{array}{l}\text { Index }(0-10) \text { expressing the level of subsidies, privileges, assistance, or support the state } \\
\text { provides for a particular religion. The closer to } 10 \text {, the higher the level of government } \\
\text { favoritism. }\end{array}$ \\
\hline$\overline{\mathrm{X}_{7}-\mathrm{SRI}}$ & $\begin{array}{l}\text { Index }(0-10) \text { stating the level of limits applied to implementing religious activities, } \\
\text { professions, or the selection of religion by groups, associations, or other religious cultures. The } \\
\text { closer to } 10 \text {, the higher the level of social regulation. }\end{array}$ \\
\hline $\begin{array}{l}\text { Y-Stock } \\
\text { Return }\end{array}$ & $\begin{array}{l}\text { Stock return is the gain (or loss) earned on the observed day }(\mathrm{t}) \text { compared to the previous day } \\
(\mathrm{t}-1) \text {. }\end{array}$ \\
\hline
\end{tabular}

Hypothesis testing was carried out using panel multiple linear regressions with the robust standard error. The regression equation is described by the following model for each variable characteristic of culture and belief:

$$
S R_{\mathrm{i}, t}=\alpha+\beta_{1} \text { Culture } / \text { Beliefi } f_{i}+\varepsilon_{\mathrm{i}, \mathrm{t}}
$$

Information:

$\mathrm{SR}=$ Stock return

$\alpha=$ Constant.

$\beta=$ Coefficient.

Culture/Belief $=$ The characteristics of the culture or belief being tested, consisting of PDI, IDV, UAI, LTO, GRI, GFI, and SRI.

$\varepsilon=$ error. 


\section{RESULTS AND DISCUSSION}

\subsection{Results}

The total observed stock returns comprised 2,960 data points taken during the celebrations of seven different belief groups. The country with the most data was Great Britain with 552 data points, with the most observations on Christian holidays and the least on popular holidays. The country with the most minor data was South Korea, with 60 data points, with the most observations on Christian holidays and the least on Buddhist holidays. The holiday with the most observations was a Christian holiday, with the most observations in Great Britain and the least in Israel. The holiday with the fewest observations was a Buddhist holiday with the most observations found in Hong Kong and were not found in Belgium, Brazil, Egypt, France, Germany, Israel, Japan, Russia, or the United Kingdom.

Table 3. Values of cultural dimension and international religion indices.

\begin{tabular}{c|c|c|c|c|c|c|c}
\hline \multirow{2}{*}{ Country } & \multicolumn{7}{c}{ Variables } \\
\cline { 2 - 8 } & PDI & IDV & UAI & LTO & GRI & GFI & SRI \\
\hline Belgium & 65 & 75 & 94 & 82 & 1.6 & 7.4 & 7.2 \\
\hline Brazil & 69 & 38 & 76 & 44 & 0.6 & 0.7 & 5.0 \\
\hline China & 80 & 20 & 30 & 87 & 8.7 & 5.2 & 4.2 \\
\hline Egypt & 70 & 25 & 80 & 7 & 8.1 & 8.3 & 7.3 \\
\hline France & 68 & 71 & 86 & 63 & 2.9 & 5.0 & 5.4 \\
\hline Germany & 35 & 67 & 65 & 83 & 2.2 & 6.3 & 5.1 \\
\hline Hong Kong & 68 & 25 & 29 & 61 & 0.6 & 4.1 & 0.6 \\
\hline Indonesia & 78 & 14 & 48 & 62 & 6.5 & 7.6 & 9.7 \\
\hline India & 77 & 48 & 40 & 51 & 5.8 & 7.0 & 9.7 \\
\hline Israel & 13 & 54 & 81 & 38 & 3.8 & 7.9 & 9.2 \\
\hline Japan & 54 & 46 & 92 & 88 & 1.0 & 1.5 & 3.7 \\
\hline South Korea & 60 & 18 & 85 & 100 & 0.5 & 4.8 & 0.2 \\
\hline Malaysia & 100 & 26 & 36 & 41 & 7.9 & 8.0 & 8.7 \\
\hline Singapore & 74 & 20 & 8 & 72 & 7.4 & 3.7 & 2.0 \\
\hline United Kingdom & 35 & 89 & 35 & 51 & 1.5 & 5.5 & 4.4 \\
\hline Russia & 93 & 39 & 95 & 81 & 5.2 & 5.3 & 9.4 \\
\hline Taiwan & 58 & 17 & 69 & 93 & 0.0 & 0.5 & 0.0 \\
\hline
\end{tabular}

Table 3 shows the values of the cultural dimension index and international religion index for each observed country. Information about the table is explained as follows:

1. The level of power distance is dominated by countries with a high level of power distance. As many as 14 countries were found to have a significant PDI value $(>50)$. Of all the countries with large PDI values, ten are in the Asian region, and four are in the European region, indicating that countries in the Asian region tend to rely more on centralized authority and submit to power more than countries in the European region.

2. The level of individualism is dominated by countries with a low level of individualism. As many as 12 countries were found to have a small IDV value $(<50)$. Out of 12 collectivist countries, two are in the European region and ten are in the Asian region. In comparison, the other five countries with large IDV values comprise four countries in the European region and one in the Asian region, which shows that countries in the European region tend to have looser bonds between people than countries in the Asian region.

3. The level of uncertainty avoidance is dominated by countries with a high level of uncertainty avoidance. As many as ten countries were found to have large UAI values $(>50)$. The countries with a significant UAI value are in the Asian region and five others are in the European region. In contrast, countries with a low UAI value comprise one country in the European region and six in the Asian region, which shows that conservatism and the spread of views on uncertainty are evenly distributed in both regions. 
4. The level of long-term orientation is dominated by countries with a high level of long-term orientation. As many as 13 countries were found to have large LTO values (> 50). Of the countries with a significant LTO value, eight of them are in the Asian region and five others are in the European region, while countries with a low LTO value comprise one country in the European region and three in the Asian region, which shows that the views on change and the future are evenly distributed in both regions.

5. The level of government regulation is dominated by countries with a low level of government regulation. As many as ten countries were found to have a small GRI value $(<50)$. Of the ten countries, five are in the European region and four are in the Asian region. In comparison, the other seven countries with large GRI values comprise one in the European region and six in the Asian region, which shows that countries in the Asian region tend to have more restrictions imposed by government on religious activities than countries in the European region.

6. The level of government favoritism is dominated by countries with a high level of government favoritism. As many as ten countries were found to have significant GFI scores $(>50)$. Of the ten countries, four are in the European region and six are in the Asian region. The other seven countries with a small GFI value comprise two countries in the European region and five in the Asian region, which shows that the government's unique behavior towards a particular belief is evenly distributed in both regions.

7. The level of social regulation is dominated by countries with a high level of social regulation. As many as nine countries were found to have high SRI values $(>50)$. Of the nine countries, four are in the European region and five are in the Asian region. The other eight countries with a small SRI value comprise two countries in the European region and six in the Asian region, which indicates that the social community's limitations or restrictions on religious activities are spread evenly in the two regions.

Table 4. Maximum and minimum values of research variables.

\begin{tabular}{c|c|c|c|c}
\hline & \multicolumn{2}{|c|}{ Maximum } & \multicolumn{2}{c}{ Minimum } \\
\hline & Value & Description & Value & Description \\
\hline PDI & 100 & Malaysia & 13 & Israel \\
\hline ADV & 89 & United Kingdom & 14 & Indonesia \\
\hline UAI & 95 & Russia & 8 & Singapore \\
\hline LTO & 100 & South Korea & 7 & Egypt \\
\hline GRI & 8.7 & China & 0 & Taiwan \\
\hline GFI & 8.3 & Egypt & 0.5 & Taiwan \\
\hline SRI & 9.7 & India \& Indonesia & 0 & Taiwan \\
\hline
\end{tabular}

Table 4 shows the maximum and minimum values for each observed variable. The highest Power Distance Index (PDI) value is 100 for Malaysia, and the lowest is 13 for Israel with a range of 87 , which indicates that the observed countries are very diverse, consisting of countries with very high and shallow power distance levels. The highest Individualism Index (IDV) value is 89 for the United Kingdom, and the lowest is 14 for Indonesia with a range of 75 , which indicates that the observed countries consist of both individualist countries with very high collectivist countries with shallow levels of individualism. The highest Uncertainty Avoidance Index (UAI) value is 95 for Russia, and the lowest is 8 for Singapore with a range of 87 , which indicates that the observed countries are very diverse, consisting of countries with very high and shallow levels of uncertainty avoidance. The highest Longterm Orientation Index (LTO) value is 100 for South Korea, and the lowest is 7 for Egypt with a range of 93, which indicates that the observed countries consist of both long-term oriented countries with a very high level of longterm orientation and short-term oriented countries with a shallow level of long-term orientation. The highest Government Regulation Index (GRI) value is 8.7 for China, and the lowest is 0 for Taiw an with a range of 8.7 , which indicates that the observed countries are very diverse, consisting of countries with high and low levels of government regulation. The highest Government Favoritism Index (GFI) value is 8.3 for Egypt, and the lowest is 
0.5 for Taiwan with a range of 7.8, which indicates that the observed countries consist of countries with high and low levels of government favoritism. The highest Social Regulation Index (SRI) value is 9.7 for India and Indonesia, while the lowest value is 0 for Taiwan with a range of 9.7, which indicates that the observed countries are very diverse, consisting of countries with very high and shallow levels of social regulation.

The regression results are shown in the Table 5 below:

Table 5. Regression test results.

\begin{tabular}{c|c|c}
\hline Variable & Coefficient & Prob. \\
\hline cons & -0.0015231 & 0.004 \\
\hline PDI & $5.87 \mathrm{e}-06$ & 0.106 \\
\hline IDV & 0.0000132 & $0.013^{*}$ \\
\hline UAI & $2.93 \mathrm{e}-06$ & 0.296 \\
\hline LTO & $-1.68 \mathrm{e}-06$ & 0.637 \\
\hline GRI & 0.0000975 & $0.018^{*}$ \\
\hline GFI & 0.0001538 & $0.021^{*}$ \\
\hline SRI & -0.0001358 & $0.012^{*}$ \\
\hline F test & 7.05 & $0.0098^{*}$ \\
\hline Note: * Significant at $\alpha=5 \%$.
\end{tabular}

\section{DISCUSSIONS}

The research shows that PDI does not affect stock returns. This result reflects the research of Darsono, Wong, Ha, Jati, \& Dewanti (2021), which has a positive coefficient for PDI but does not support the study which states that PDI has a positive impact on sustainable stock returns in the Asian region. The majority of the countries studied have large PDI values. There are 3 out of 5 countries in Europe and 9 out of 10 countries in Asia. Based on these figures, the proportion of countries with high PDI values is more significant in the Asian region than in Europe. Significant differences can occur because there are differences in the samples in the two studies. The majority of the samples in this study are countries in the Asian region and support (Darsono et al., 2021) regarding the positive impact of PDI, but countries in the European region were not part of the study. Bochner \& Hesketh (1994) stated that countries with high levels of power distance are reluctant to refute directives from the authorities. In the observational data, the countries with the three largest PDI, GRI, and GFI values are the majority countries with the highest average returns.

The results of the research show that IDV does affect stock returns. This result supports the research of Darsono et al. (2021), which states that IDV positively impacts sustainable stock returns in the Asian region. The majority of the studied countries have low IDV scores, indicating that most of them are collectivist countries. Of the ten collectivist countries, one is in the European region, and nine others are in the Asian region, indicating that most countries in the Asian region are collectivist countries while most countries in Europe are individualist countries. This result proves the general statement supported by Nguyen \& Truong (2013) regarding western cultures being associated with individualism and eastern cultures associated with high collectivism. Individualist societies are more concerned with their own interests (Hofstede, 2001) and follow a specific culture. They are not easily influenced by foreign cultures (Plopeanu et al., 2012). The research sample reflects that $60 \%$ of countries with higher IDV values only commemorate the holidays of the beliefs held by most citizens and do not commemorate the holidays of other belief systems. People in individualist countries who observe celebrations only for the holidays of the majority belief system show enthusiasm for the celebration of their firmer beliefs. These countries also produce higher returns than collectivist countries, which commemorate the holidays of many different beliefs.

The research demonstrates that the Uncertainty Avoidance Index does not affect stock returns. This result reflects the research of Darsono et al. (2021), which found a positive coefficient for UAI but does not support the study which states that UAI has a positive impact on sustainable stock returns in the Asian region. The countries studied are evenly divided between countries with significant UAI scores and countries with more minor UAI 
scores, with $50 \%$ of countries in the Asian region and $80 \%$ of countries in the European region having significant UAI scores. This result shows that people in the European region have a greater level of discomfort with uncertainty, so they view new culture as something foreign and choose to stick to their existing culture (Nguyen \& Truong, 2013). Regarding countries with a significant UAI value, 63\% celebrate holidays according to the predominant religion, and $60 \%$ of these countries are in the European region. This result shows that countries with high levels of uncertainty avoidance tend to stick to what they are familiar with, the belief that has long existed in society and is held by the majority of the population, which is more commonly found in the European region. Of countries with large UAI values, $63 \%$ have more significant stock price fluctuations than countries with small UAI values but commemorate holidays of many different religions. This result supports the research by Tan et al. (2019), which states that UAI negatively affects trading size, frequency, and volume. In this study, countries with high uncertainty avoidance tend to show more expressions of mood during the pre-holiday periods if the commemorated day is part of the majority belief; therefore, the stock price fluctuations are more significant in these countries.

According to these results, LTO does not affect stock returns. This contradicts Darsono et al. (2021), who state that LTO has a positive impact on sustainable stock returns in the Asian region. The majority of the countries studied have large LTO values. The 11 countries comprise four in out of five in Europe and seven out of ten in Asia. Based on these figures, the proportion of countries with high LTO scores is more significant in Europe region than in Asia. Countries with a long-term orientation develop themselves, focus on the future, and are not tied to the past and traditions (Hofstede, 2001), so the national majority belief is assumed not to be a barrier to investment decisions, and these countries do not demonstrate mood changes. As found in this study, there is no effect on stock returns within the majority of the sampled countries with large LTO values. From the 11 countries with significant LTO scores, $82 \%$ observe religious holidays of various kinds and do not focus solely on religious celebrations for the majority of religions. This result shows that long-term oriented countries are more open and tolerant of diversity and are more likely to form a society that accepts and incorporates new cultures.

The results of the research also show that GRI affects stock returns. The countries that compose most of the research sample have a small GRI value, nine countries consisting of four in Asia and five in Europe, while the six other countries with a significant GRI value are in the Asian region. All countries with large GRI values commemorate the holidays of various religions, and it was found that the most significant share returns were found during the commemoration of religious holidays with the majority of followers nationally. Grim (2014) states that violence is unavoidable when the government limits or regulates religious activities. Based on this, it is assumed that countries with a high level of government regulation tend to only commemorate the holidays of the majority belief or do not have stock returns that differ during the times of other religious celebrations. However, the study results show that holidays are not celebrated exclusively for the majority belief in countries with a high GRI level, although there are differences between returns for the majority and non-majority believers. Al-Ississ (2015) investigated the impact of mood on stock returns during the commemoration of holidays where the majority follow the primary religion (Islam) in ten Muslim countries. Celebration based on a positive commemoration will form a positive mood resulting in increased stock returns, while a celebration based on a time of mourning will form a negative mood and result in reduced stock returns (Al-Ississ, 2015). Additionally, regulations imposed by the government that trigger public anger (Grim, 2014) can destroy the mood. However, the study results found that the average return of countries with a significant GRI value was higher than countries with a small GRI value even though with a high level of government regulation non-majority holidays were still celebrated.

In terms of the level of government favoritism, the results show that this positively affects stock returns. The majority of countries sampled have high GFI scores, namely nine countries consisting of six out of ten countries in Asia and three out of five countries in Europe. Despite having a high level of favoritism, only $22 \%$ of countries with high GFI scores observe celebrations solely for the majority faith, while others celebrate holidays of various faiths. 
In countries that commemorate the holidays of various belief systems, the majority have the most significant or most minor returns during holidays with the most prominent and smallest number of adherents to faith, so it can be distinguished from other religious celebrations that are neither majority nor minority. Research by Khan et al. (2018) shows that government favoritism towards a particular belief can affect people's preferences. Additionally, Khan et al. (2018) proved that non-Christians in United Kingdom also celebrate Christmas, a Christian holiday, due to the government's strong support of the celebration every year from economic matters to live broadcasts from heads of state. This can build the mood of the population nationally ahead of the commemoration of the holiday so that it can influence investment decisions and increase or decrease stock returns. In this study, $44 \%$ of countries with significant GFI scores had the most considerable returns during holidays with the most adherents.

Finally, this study shows that the level of social regulation has a negative effect on stock returns. The countries in the research sample are divided relatively evenly between countries with large and small SRI scores. A total of eight countries have high SRI scores, namely five out of ten countries in Asia and three out of five countries in Europe, while seven other countries have low SRI scores. Out of these eight countries, 63\% celebrate holidays of various faiths while the rest only commemorate the religious holidays of the religion with the most adherents. Out of the countries with large SRI values, it was found that $63 \%$ of them had the highest returns during the commemoration of holidays with the highest number of adherents to the majority faith nationally. Grim \& Finke (2006) stated that although the sources of social regulation are more challenging to understand, they can have consequences as substantial as government regulation. Based on this statement, it is assumed that in countries with large SRI values, the highest stock returns will be found during holidays with the highest number of adherents to the majority belief and the lowest stock returns on holidays with the lowest number of followers of minority faiths. The data of this study indicate that in countries with large SRI values, only $25 \%$ of the lowest stock returns are found on holidays related to minority faiths. This shows that the level of social regulation suppresses the formation of mood for celebrations with the lowest number of adherents. However, the study results support the assumption that large SRI values produce significant returns during holidays of the majority religion through their positive impact according to statistical calculations.

This study showed that investors' behavior is determined by cultural characteristics and government action and policy. Asia and Europe have different cultures, and these results indicate that differences in culture can drastically affect stock returns (Chancharat, Maporn, Phuensane, \& Chancharat, 2020). Many Asian countries are more religious, more socially diverse, and have more centralized governments, while European countries are secular, more homogenous, and have more democratic governments (Salerno, 2021). This study also proves that, in the context of stock investments, rationality can be bounded by several socio-political contexts (Tuyon \& Ahmad, 2018).

\section{CONCLUSIONS}

The study found that the cultural characteristics that influence stock returns during religious holidays are only individualism variables, while all belief characteristic variables, namely government regulation, government favoritism, and social regulation, influence stock returns during religious holidays. Based on these results, it is recommended that investors identify the stock market characteristics where investment is intended to facilitate investment decisions more quickly. During holidays where the majority of citizens adhere to the primary religion, it is recommended that investors take full advantage of the positive impact that this has on stock returns in individualist countries, countries with high levels of government regulation and privilege, and high levels of social regulation. Further research is recommended with the use of samples that better reflect international market conditions to produce more reliable information. Future research could also use other variables that describe the characteristics of culture and belief more accurately. 
Funding: This study received no specific financial support.

Competing Interests: The authors declare that they have no competing interests.

Acknowledgement: All authors contributed equally to the conception and design of the study.

\section{REFERENCES}

Al-Ississ, M. (2015). The holy day effect. Journal of Behavioral and Experimental Finance, 5(C), 60-80.

Bley, J., \& Saad, M. (2010). Cross-cultural differences in seasonality. International Review of Financial Analysis, 19(4), 306-312. Available at: https://doi.org/10.1016/j.irfa.2010.08.004.

Bochner, S., \& Hesketh, B. (1994). Power distance, individualism/collectivism, and job-related attitudes in a culturally diverse work group. Journal of Cross-Cultural Psychology, 25(2), 233-257. Available at: https://doi.org/10.1177/0022022194252005.

Chancharat, S., Maporn, S., Phuensane, P., \& Chancharat, N. (2020). Volatility of holiday effects in Thai stock market. Kasetsart Journal of Social Sciences, 41(2), 401-406. Available at: https://doi.org/10.1016/j.kjss.2018.08.001.

Cheon, Y.-H., \& Lee, K.-H. (2018). Maxing out globally: Individualism, investor attention, and the cross section of expected stock returns. Management Science, 64(12), 5807-5831. Available at: https://doi.org/10.1287/mnsc.2017.2830.

Costa, D. F., Carvalho, F. d. M., \& Moreira, B. C. d. M. (2019). Behavioral economics and behavioral finance: A bibliometric analysis of the scientific fields. Journal of Economic Surveys, 33(1), 3-24. Available at: https://doi.org/10.1111/joes.12262.

Darsono, S. N., Wong, W.-K., Ha, N. T., Jati, H. F., \& Dewanti, D. S. (2021). Cultural dimensions and sustainable stock exchanges returns in the Asian region. Journal of Accounting and Investment, 22(1), 133-149.

De Anca, C., \& Aragón, S. (2018). The 3 types of diversity that shape our identities. Harvard Business Revierw, 5(24), 2-5.

Dou, P., Truong, C., \& Veeraraghavan, M. (2016). Individualism, uncertainty avoidance, and earnings momentum in international markets. Contemporary Accounting Research, 33(2), 851-881. Available at: https://doi.org/10.1111/19113846.12155 .

Edwards, W. (1968). Conservatism in human information processing. In B. Kleinmuntz (Ed.), Formal Representation of Human Judgment (pp. 17-52). New York: Wiley.

Flammer, C., \& Bansal, P. (2017). Does a long-term orientation create value? Evidence from a regression discontinuity. Strategic Management Journal, 38(9), 1827-1847. Available at: https://doi.org/10.1002/smj.2629.

Gaganis, C., Hasan, I., Papadimitri, P., \& Tasiou, M. (2019a). National culture and risk-taking: Evidence from the insurance industry. Journal of Business Research, 97, 104-116. Available at: https://doi.org/10.1016/j.jbusres.2018.12.037.

Grim, B. J., \& Finke, R. (2006). International religion indexes: Government regulation, government favoritism, and social regulation of religion. Interdisciplinary Journal of Research on Religion, 2(1), 1 - 38.

Grim, B. J. (2014). Growing religion and growing religious restrictions: A global overview. International Area Studies Review, 17(2), 134-145. Available at: https://doi.org/10.1177/2233865914537054.

Hofstede, G. (2001). Culture's consequences: Comparing values, behaviors, institutions, and organizations across nations (2nd ed.). London: Sage Publications.

Hofstede., G. (1980). Culture's consequences: International differences in work-related values. London: Sage Publications.

Huang, Y., Miao, J., \& Wang, P. (2019). Saving China's stock market? IMF Economic Review, 67, 349-394. Available at: https://doi.org/10.1057/s41308-019-00079-z.

Ji, L. J., Zhang, Z., \& Guo, T. (2008). To buy or to sell: Cultural differences in stock market decisions based on price trends. Journal of Behavioral Decision Making, 21(4), 399-413. Available at: https://doi.org/10.1002/bdm.595.

Khan, A., Lindridge, A., \& Pusaksrikit, T. (2018). Why some South Asian muslims celebrate Christmas: Introducing 'acculturation trade-offs. Journal of Business Research, 82(1), 290-299. Available at: https://doi.org/10.1016/j.jbusres.2017.07.023. 
Lai, Y.-W., \& Windawati, A. (2017). Risk, return, and liquidity during Ramadan: Evidence from Indonesian and Malaysian stock markets. Research in International Business and Finance, 42, 233-241. Available at: https://doi.org/10.1016/j.ribaf.2017.04.054.

Laufer, D., Garrett, T. C., \& Ning, B. (2018). The moderating role of power distance on the reaction of consumers to the CEO as a spokesperson during a product harm crisis: Insights from China and South Korea. Journal of International Management, 24(3), 215-221. Available at: https://doi.org/10.1016/j.intman.2017.12.002.

Lingaraja, K., Paul, J., \& Selvam, M. (2019). Indian culture, lunar phases and stock market returns. International Journal of Indian Culture and Business Management, 19(4), 394-417. Available at: https://doi.org/10.1504/ijicbm.2019.104783.

Mansour, W., \& Jlassi, M. (2014). The effect of religion on financial and investing decisions. In H. K. Baker, \& V. Ricciardi, Investor Behavior: The Psychology of Financial Planning and Investing. New York: John Wiley \& Sons, Inc.

Nguyen, N. H., \& Truong, C. (2013). The information content of stock markets around the world: A cultural explanation. Journal of International Financial Markets, Institutions and Money, 26, 1-29. Available at: https://doi.org/10.1016/j.intfin.2013.03.001.

Nofsinger, J. R. (2005). Psychology of investing (2nd ed.). New Jersey: Prentice Hall Inc.

Plopeanu, A.-P., Brailean, T., \& Arsene, M. (2012). Religious freedom indexes, cultural dimensions, and welfare in Europe. EDULEARN12 (pp. 1875-1883). Barcelona: International Association of Technology, Education and Development (IATED).

Robins, R. P., \& Smith, G. P. (2019). On structural changes in the holiday effect. The Journal of Wealth Management, 21(4), 98105. Available at: https://doi.org/10.3905/jwm.2019.21.4.098.

Rossi, M., \& Gunardi, A. (2018). Efficient market hypothesis and stock market anomalies: Empirical evidence in four European countries. Journal of Applied Business Research, 34(1), 183-192. Available at: https://doi.org/10.19030/jabr.v34i1.10111.

Rossi, M., Marcarelli, G., Ferraro, A., \& Lucadamo, A. (2020). How do calendar anomalies affect an investment choice: A proposal of an analytic hierarchy process model. International Journal of Economics and Financial Issues, 10(1), $244-249$. Available at: https://doi.org/10.32479/ijefi.8995.

Salerno, D. (2021). How national culture affects IPO decisions? Evidence from Europe and Asia. Journal of Asia Business Studies, 15(3), 457 - 483. Available at: https://doi.org/10.1108/jabs-06-2020-0218.

Setayesh, M. H., \& Daryaei, A. A. (2017). Good governance, innovation, economic growth and the stock market turnover rate. The Journal of International Trade $\&$ Economic Development, 26(7), 829-850. Available at: https://doi.org/10.1080/09638199.2017.1334809.

Sharma, A., \& Kumar, A. (2019). A review paper on behavioral finance: Study of emerging trends. Qualitative Research in Financial Markets, 12(2), 137-157. Available at: https://doi.org/10.1108/qrfm-06-2017-0050.

Shen, H., Wu, H., \& Chand, P. (2017). The impact of corporate social responsibility assurance on investor decisions: Chinese evidence. International Journal of Auditing, 21(3), 271-287. Available at: https://doi.org/10.1111/ijau.12094.

Tan, G., Cheong, C. S., \& Zurbruegg, R. (2019). National culture and individual trading behavior. Journal of Banking \& Finance, 106, 357-370. Available at: https://doi.org/10.1016/j.jbankfin.2019.07.007.

Tuyon, J., \& Ahmad, Z. (2018). Psychoanalysis of investor irrationality and dynamism in stock market. Journal of Interdisciplinary Economics, 30(1), 1-31. Available at: https://doi.org/10.1177/0260107917697504.

Wasiuzzaman, S., \& Al-Musehel, N. A. (2018). Mood, religious experience and the Ramadan effect. International Journal of Emerging Markets, 13(1), 290-307. Available at: https://doi.org/10.1108/ijoem-01-2017-0001.

Views and opinions expressed in this article are the views and opinions of the author(s), Asian Economic and Financial Review shall not be responsible or answerable for any loss, damage or liability etc. caused in relation to/arising out of the use of the content. 